
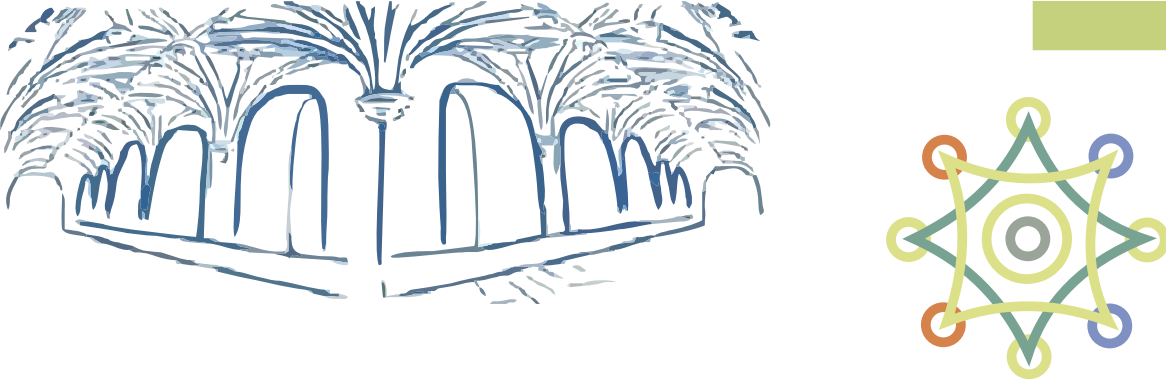

R E V I S T A

PRACTICUM

Número 5(1), Enero-Junio, 2020

ISSN: $2530-4550$

Oliveira, I.; Santos, P.; Guedes, A. \& Antunes, S. (2020).

Competências e estágio nalicenciatura de Secretariado

de Administração. Revista Practicum, 5(1), 121-139

Fecha de recepción: 30-04/2020

Fecha de aceptación: 08-06/2020

DOI: 10.24310/RevPracticumrep.v5i1.9834

\title{
Competências e estágio na licenciatura de Secretariado de Administração
}

Skills and internship in Secretarial studies and administrative assistance bachelor

\section{Competencias e prácticas curriculares en el grado de Secretaría de Administración}

Isabel Oliveira

Escola Superior de Tecnologia e Gestão de Lamego

ioliveira@estgl.ipv.pt

Paula Santos

Escola Superior de Tecnologia e Gestão de Lamego

psantos@estgl.ipv.pt

Anabela Guedes

Escola Superior de Tecnologia e Gestão de Lamego aguedes@estgl.ipv.pt

Sandra Antunes

Escola Superior de Tecnologia e Gestão de Lamego santunes@estgl.jpv.pt

\section{Resumo}

As exigências do mundo do trabalho e a uniformização a que assistimos no espaço comunitário europeu, ao nível do Ensino superior, têm exigido que os 
curricula sejam desenhados e pensados de acordo com as competências que os alunos têm de alcançar. $O$ presente trabalho procura analisar a forma como as competências e objetivos são consolidados durante o estágio realizado no sexto semestre da licenciatura de Secretariado de Administração. Além da pesquisa exploratória e bibliográfica, foi utilizado o método de estudo de caso, com base em todos os relatórios de estágio realizados e apresentados pelos alunos (estudo de multicasos), entre 2012 e 2018, com o objetivo de identificar quais as competências mais solicitadas pelas entidades de acolhimento e aquelas que têm sido mais trabalhadas pelos alunos.

\section{Abstract}

The current demands of the world of work and the uniformity we see in the European Community, at the level of higher education, have required curricula to be designed and thought of according to the skills that students need to achieve. This paper seeks to analyze how competencies and objectives are consolidated during the internship held in the sixth semester of the Secretarial studies degree. In addition to exploratory and bibliographic research, the case study method was used based on all internship reports conducted and presented by students (multicase study). The internship reports were produced between 2012 and 2018, with the objective of identifying which competencies were most requested by the host entities and those that have been most worked by the students during their degree.

\section{Resumen}

Las demandas del mundo del trabajo y la estandarización que vemos en el espacio de la comunidad europea, a nivel de educación superior, han requerido que los planes de estudio se diseñen y diseñen de acuerdo con las habilidades que los estudiantes deben lograr. El presente trabajo busca analizar cómo se consolidan las competencias y objetivos durante la pasantía realizada en el sexto semestre del grado de Secretaría de Administración. Además de la investigación exploratoria y bibliográfica, se utilizó un método de estudio de caso, basado en todos los informes realizados y presentados por los estudiantes (casos múltiples), entre 2012 y 2018, con el objetivo de identificar qué habilidades fueron más solicitadas por las entidades anfitrionas y los que más han trabajado los estudiantes.

\section{Palavras chave}

Ensino superior, secretário contemporâneo, competências críticas e transversais, objetivos científicos e técnicos. 


\section{Keywords}

Higher education, contemporary administrative assistant, hard and soft skills, scientific and technical goals.

\section{Palabras clave}

Enseñanza superior, secretario contemporáneo, competencias centrales y transversales, objetivos científicos y técnicos.

\section{Introdução}

A licenciatura de secretariado de administração, em funcionamento ininterrupto desde 2006, na instituição de ensino superior em estudo neste trabalho (a qual pertence ao subsistema politécnico e ao setor público) tem vindo a desenvolver um conjunto de adaptações e reestruturações. Estas têm sido efetuadas quer ao nível dos conteúdos programáticos, quer das unidades curriculares que fazem parte do plano de estudos deste 10 ciclo. Este processo teve sempre em consideração as mudanças que se verificam no perfil dos seus alunos, bem como as solicitações apresentadas pelo mercado de trabalho, além daquelas que têm sido exigidas, ao longo dos últimos anos, pelas instâncias educativas (nacional e da União Europeia), no sentido de oferecer uma qualificação que seja adequada, pertinente, reconhecida pelos pares e atualizada (reconhecida pelas entidades patronais, enquanto entidades recetoras dos recursos humanos qualificados).

Podemos sistematizar as principais adaptações / alterações realizadas da seguinte forma:

- Adaptações de acordo com o processo de Bolonha (European Ministers in charge of Higher Education, 1999)- a licenciatura foi reformulada, de forma a apresentar um plano curricular definido para seis semestres (no seu início, contemplava doze semestres), de acordo com uma construção de um percurso formativo, dividido em horas de trabalho e ECTS (european credit transfer system), de forma a garantir o reconhecimento do ciclo de estudos em todo o espaço de ensino da União Europeia, bem como a possibilidade de mobilidade de alunos e estudantes (dada a possibilidade de estabelecimento de parcerias com outras instituições de ensino superior com ciclos de estudo iguais ou equivalentes), através da adoção da Lei de Bases do Sistema Educativo (Lei n. ${ }^{\circ}$ 49/2005 de 30 de Agosto da Assembleia da República, 2005) e legislação posterior;

- Adaptações de acordo com as avaliações da A3ES (Agência de Avaliação e Acreditação do Ensino Superior) - a licenciatura procurou clarificar os objetivos gerais e específicos, bem como as competências científicas, técnicas, nucleares 
e as soft skills de cada unidade curricular, para que, de forma concertada, conduzisse à aquisição de todos conhecimentos e competências em que o perfil do secretário contemporâneo se prefigura. De facto, nesta licenciatura foram realizados, ao longo dos anos, diversos ajustamentos, para adequar a mesma aos critérios de excelência exigidos pela A3ES. Nomeadamente, a redução do número de semestres da licenciatura para apenas 6 , reestruturação de algumas unidades curriculares, organização das unidades curriculares por áreas científicas, sistematização dos objetivos e competências de cada unidade curricular, desenvolvimento de atividades de investigação na área de secretariado com participação de alunos, reforço das publicações científicas, entre muitas outras. Todas essas adaptações garantiram a este ciclo de estudos a sua creditação máxima concedida pela A3ES, por seis anos letivos;

- A licenciatura alterou o seu regime de funcionamento há cerca de três anos letivos, dada a verificação da alteração substancial do perfil dos alunos candidatos à sua frequência, passando de regime noturno, para regime diurno (Despacho (extrato) n. ${ }^{\circ} 4684 / 2016,2016$ ). Se até 2016 , a maioria dos alunos que se candidatavam a este ciclo de estudos tinham um perfil de trabalhadores-estudantes (sendo já ativos no mercado de trabalho e buscando atualização de conhecimentos e melhoria da sua qualificação), a partir desse ano a maioria dos candidatos passou a caracterizar-se como jovens acabados de terminar a sua formação secundária e ingressando na licenciatura através do Concurso Nacional de Acesso;

- Em termos gerais, a licenciatura tem procurado reforçar a vertente prática e de ensino colaborativo, procurando que os alunos tenham um papel pró-ativo ao longo de toda a sua formação superior, além do desenvolvimento de alguns projetos de investigação (onde os alunos são incluídos), bem como no aumento de publicações e realização de comunicações científicas, na área do secretariado e noutras áreas importantes para o ciclo de estudos (ESTGL, 2019);

- Finalmente, têm sido angariadas cada vez mais entidades para realização de estágios (que têm lugar no 60 semestre da licenciatura), garantindo a qualidade e a variedade das entidades de acolhimento, tendo representadas organizações do setor lucrativo (empresas de diversas atividades económicas), do terceiro setor (organizações sociais e/ou sem fins lucrativos), além de entidades da administração pública (ESTGL, 2019).

A realização da unidade curricular de Projeto/Estágio tem, por isso, procurado conceder aos alunos um espaço de consolidação de todas as competências e conhecimentos considerados essenciais à prática do secretariado contemporâneo e qualificado, fazendo uso das competências adquiridas ao longo dessa mesma formação, desde as competências tradicionais relacionadas com o apoio administrativo (assessoria, tarefas de ligação, arquivo, etc.), até à utilização de ferramentas ino- 
vadoras ligadas às TIC (gestão documental, ferramentas multimédia, entre outras) e à gestão (conhecimentos de informação contabilística, direito comercial, etc.), passando ainda pela assessoria especializada baseada na utilização de línguas estrangeiras e protocolo, entre tantas outras, igualmente relevantes.

Neste estudo tentámos, assim, identificar quais as competências mais solicitadas durante a realização dos estágios, nas diferentes entidades de acolhimento no período em estudo.

\section{Contextualização / enquadramento teórico}

Falar de ensino superior e dos seus desafios, nos nossos dias, implica perceber de que forma as licenciaturas (e até mesmo muitos mestrados) são pensadas e construídas, baseando-se em constructos teóricos de definição de objetivos e aquisição de competências. Qualquer ciclo de estudos é estruturado e construído com base num conjunto de objetivos gerais, que se desdobram em objetivos específicos, trabalhados nas diferentes unidades curriculares (organizadas em áreas científicas estruturantes e áreas científicas complementares), as quais ainda buscam estratégias e metodologias de trabalho que garantam o alcance desses objetivos e a verificação dos mesmos através de competências científicas, técnicas e pessoais.

O conceito de competência tem vindo a evoluir desde as décadas de 19701980, evidenciando-se com um lugar central neste processo de ensino aprendizagem. Le Boterf (2001) situa a competência numa encruzilhada, com três eixos formados: pela pessoa (a sua biografia, a forma da sua socialização), pela sua formação educacional e pela sua experiência profissional. A competência é, por isso, para este autor, o conjunto de aprendizagens sociais e comunicacionais nutridas a montante pela aprendizagem e pela formação e a jusante pelo sistema de avaliações. Segundo ainda o mesmo autor, a competência é vista como um saber agir responsável e que é reconhecido pelos outros enquanto tal. Implica saber como mobilizar, integrar e transferir os conhecimentos, recursos e habilidades/competências, num contexto profissional determinado.

De acordo com os estudos de Spencer, Mcclelland, \& Spencer (1990), a competência, por outro lado, é considerada como uma característica subjacente a uma pessoa que é casualmente relacionada com o desempenho superior na realização de uma tarefa ou em determinada situação. De acordo com esta definição e com a proposta teórica destes autores, apresenta-se uma diferenciação entre as ideias de competência de aptidão, sendo esta última vista como um talento natural da pessoa, o qual pode vir a ser aprimorado, de habilidades, demonstração de um talento particular na prática e conhecimentos: o que as pessoas precisam saber para desempenhar uma tarefa. 
Assim, tendo em conta os diversos contributos, podemos definir uma competência como o conjunto de qualidades e comportamentos profissionais que mobilizam os conhecimentos técnicos e permitem agir na solução de problemas, estimulando desempenhos profissionais superiores e alinhados com a estratégia da organização (Camara, 2017, p. 15). Ou seja, as competências medem-se pelos resultados (outputs), mas para que esses comportamentos gerem desempenhos superiores é necessário que, a montante, existam valores, traços de personalidade, motivações e autoconceito capazes de lhes dar origem (inputs). Isto corresponde "à distinção existente em inglês entre competences, que são os outputs medidos em termos de desempenho profissional do indivíduo, e competencies, que são os inputs que essa pessoa traz para a sua atividade, suscetíveis de resultarem num desempenho superior" (Ramos \& Bento, 2006, p. 80).

Em síntese, concordamos com a ideia de a competência ser "um saber agir responsável e reconhecido, que implica mobilizar, integrar, transferir conhecimentos, recursos e habilidades, que agreguem valor econômico à organização e valor social ao indivíduo" (Fleury \& Fleury, 2001, p. 189), ou, de acordo com o estipulado no Quadro Europeu das Qualificações,

a capacidade comprovada de utilizar o conhecimento, as aptidões e as capacidades pessoais, sociais e/ou metodológicas, em situações profissionais ou em contextos de estudo e para efeitos de desenvolvimento profissional e/ou pessoal. No âmbito do Quadro Europeu de Qualificações, descreve-se a competência em termos de responsabilidade e autonomia (Comissão Europeia, 2009, p. 11).

Perante estes critérios, a Escola (independentemente do nível de ensino onde cada uma se posiciona), enquanto instituição de promoção da cidadania, tem um papel central na formação dos indivíduos e na consolidação das suas competências (especialmente as instituições de ensino superior)(Cabrera-Jimenez, 2020), concedendo aos seus alunos espaços de reflexão crítica e momentos que lhes permitam intervir na comunidade, de acordo com as necessidades indicadas por esta, nas áreas onde se estão a qualificar / especializar, potencializando simultaneamente a sua empregabilidade e mesmo a inclusão e coesão sociais. Dessa forma, o ensino superior contribuirá para a preparação de "ciudadanos propositivos y con alto grado de sentido de pertenencia, expresado en empoderamiento y participación ciudadana" (Cabrera-Jimenez, 2020, p. 3).

Ou seja, a formação superior deve promover

a aquisição de uma gama de aptidões e competências que vão desde a consolidação das designadas hard skills ou competências técnicas (profissionais) (passando, na formação qualificada de secretariado, pelas competências ao nível da organização e da gestão do tempo, da avaliação e da produção de 
informação, pelas competências ao nível do planeamento ou da gestão documental), até às soft skills ou competências comportamentais (interpessoais) competências comunicacionais e negociais, aptas a desempenhar funções de gestão de conflitos ao nível das organizações (Santos \& Bonito, 2010).

Essa conjugação de saberes implica, por isso, a própria conjugação de esforços entre as instituições de ensino e as entidades / organizações empregadoras, promovendo-se uma cooperação estratégica para melhorar a competitividade, a qualidade e a produtividade de todos os stakeholders presentes no mercado, através de uma responsabilidade partilhada, onde se evidenciam três vetores indissociáveis: o saber interagir, o poder interagir e o querer interagir (Le Boterf, 2001; Vandeweerd et al., 2014). Ou seja, defendemos que a competitividade das organizações só será possível se estas tiverem aos dispor e apostarem em recursos humanos qualificados e competentes, mesmo que isso implique um aumento dos custos fixos organizacionais.

Para existir esse diálogo e convergência entre o mundo do trabalho e as entidades de formação superior, teremos de apostar em diversos métodos que confluam na aquisição e consolidação de todas as competências profissionais, preparando os futuros profissionais a três níveis fundamentais: aliando o saber-saber (conhecimento científico, abstrato e subjetivo, capaz de ser adaptado a situações reais), o saber-estar (postura e assertividade perante os mais diversos ambientes profissionais) e o saber-fazer (realização de tarefas concretas, enquanto profissionais especializados, de forma eficiente, através da aplicação dos quadros teóricos abstratos) de forma integrada. Desta forma, o aluno e futuro profissional conseguirá mobilizar e conjugar todas essas capacidades para conseguir resolver novas situações (Le Boterf, 2001), ou seja, conseguir mobilizar os conhecimentos perante qualquer situação, no momento certo e com discernimento (Perrenoud, 1999; Vandeweerd et al., 2014)

Ou, por outras palavras, o ensino superior deverá conseguir preparar os profissionais para a convergência de diversas competências que sejam capazes de responder às necessidades do mundo do trabalho:

"technical (cognitive knowledge), methodological (research), participatory (knowing how to be with others) and personal (ethical). Therefore, competencies are not innate potentialities of the human being, but rather form part of a permanent construction on the part of a teacher, based on a clear intention to produce or carry out a specific task efficiently and effectively" (Martínez, Mendoza Velazco, Cejas, Villacis, \& Freire, 2019, pp. 356-357).

A área da formação superior em secretariado tem ganhado cada vez maior interesse, dada a abrangência de áreas do saber que este profissional tem de dominar pela inerente e necessária abrangência das áreas profissionais que pode 
apoiar/suportar, bem como da imprescindível capacidade de polivalência e adaptabilidade que deve ter. A formação de um profissional de secretário qualificado deve deter, por isso, a capacidade de conseguir desenvolver o seu trabalho de forma eficiente no mercado atual:

o secretário contemporâneo será o profissional que desenvolve a sua atividade na área do apoio administrativo e da assessoria direta e que se pauta pela eficiência, pela compreensão e visão sistémica da organização onde desempenha a sua atividade e que contribui de forma pró-ativa e assertiva para a obtenção dos objetivos estratégicos organizacionais. Com esta proposta de definição, não queremos dizer que o secretário substitui os profissionais especializados de cada área do saber, mas sim apoia no alcance dos objetivos, facilita a realização das iniciativas para alcançar as metas e indicadores traçados e promove a eficiência comunicacional nas organizações (maximizando recursos, contribuindo para a boa imagem integrada e constituindo-se como elo comunicacional aos níveis intra e extraorganizacional)(Santos, 2019, pp. 13-14).

\section{Metodologia}

O estudo que agora apresentamos segue a metodologia qualitativa, fundamentando-se na pesquisa bibliográfica e exploratória. Além do enquadramento bibliográfico sobre a concetualização da "competência", foi também realizada uma análise de conteúdo dos 28 relatórios de estágio que o período escolhido abrange, identificando os principais objetivos definidos de acordo com o interesse de cada entidade de acolhimento e as competências que os alunos tiveram de direta ou indiretamente demonstrar e trabalhar para a prossecução de todas as tarefas realizadas. Assim, podemos dizer que análise de conteúdo permite a articulação entre uma descrição analítica do conteúdo dos documentos selecionados (relatórios de estágio), segundo procedimentos sistemáticos e objetivos, e o realçar do sentido ou significado desse conteúdo, por meio de deduções lógicas e justificadas dos fatores que determinaram as suas caraterísticas, tendo como referência o contexto da mensagem e os seus efeitos (Bardin, 2011).

Tendo em conta o exposto no enquadramento teórico, procurámos perceber quais as competências mais solicitadas pelas entidades de acolhimento dos estágios, dos alunos de 3. ano da licenciatura em Secretariado de Administração, tendo em conta não só a sua natureza, mas também de acordo com os objetivos negociados para cada aluno e com as tarefas desenvolvidas durante esse período. Dessa forma, procurámos sistematizar as competências mais referidas ao longos do corpus documental, para as conseguirmos quantificar (Fortin, 2000) e tratar de acordo com os objetivos estabelecidos para este trabalho. 
Assim, a questão de partida deste primeiro estudo exploratório consiste na seguinte: "De que forma as competências nucleares e transversais, desenvolvidas ao longo do plano curricular de Secretariado de Administração são utilizadas e consolidadas no estágio final?"

Como objetivos, enunciámos os seguintes:

1. Identificar os objetivos e competências presentes na realização dos estágios;

2. Perceber quais as competências cientificas e técnicas (hard skills), bem como as soft skills mais trabalhadas nos estágios, de acordo com os interesses e natureza das entidades de acolhimento;

3. Perceber de que forma, no futuro, poderá ser feito um estudo exaustivo sobre competências e inserção dos alunos e licenciados em Secretariado de Administração no mercado de trabalho.

Em termos de delimitação do universo, foram recolhidos todos os trabalhos finais de licenciatura de secretariado de administração, desde o ano letivo 20122013 até ao ano de 2017-2018. Embora a licenciatura de secretariado de administração já se encontre em funcionamento na instituição desde o ano letivo de 2006-2007, definimos como primeiro ano de análise o ano letivo em que esta licenciatura foi avaliada pela A3ES, que definiu o plano curricular que está em funcionamento até ao momento e obteve a sua acreditação de funcionamento por um período de 6 anos letivos.

Em termos de universo, gostaríamos ainda de realçar o facto de apenas nos termos debruçado sobre os alunos e trabalhos referentes à realização de projetos em contexto organizacional (estágio), dado que esta unidade permite (e foi um dos pontos fortes referido pela A3ES na sua avaliação) a conclusão da licenciatura através da escolha de uma possibilidade de entre três existentes: projeto de empreendedorismo (criação ou revitalização de uma empresa), projeto de investigação-ação (desenvolvimento de propostas de melhoria e maior competitividade de tarefas relacionadas com a função de secretariado) ou projeto em contexto organizacional (estágio de $\mathbf{3 0 0}$ horas numa entidade de acolhimento). Os dados foram depois trabalhados de acordo com o número de ocorrências para cada item a identificar e as competências definidas.

Em termos gerais, podemos identificar os seguintes indicadores que são trabalhados nas unidades curriculares (especialmente nas que pertencem à área científica de Secretariado) e que procuramos consolidar e verificar com a realização dos estágios: 


\section{Áreas de formação}

- Receção e atendimento presencial e telefónico;

- Tarefas de apoio administrativo;

- Gestão documental e Arquivo;

- Planeamento;

- Otimização das TIC de apoio às tarefas administrativas;

- Gestão de eventos.

\section{Competências técnicas}

- Gestão de fluxos de informação;

- Capacidade de gestão de tempo;

- Domínio de línguas estrangeiras;

- Negociação;

- Conhecimento de cerimonial e etiqueta;

- Habilidade de comunicação;

- Capacidade de resolução de problemas;

- Apoio à gestão e planeamento estratégico;

- Capacidade de organização;

- Conhecimento e utilização de TIC.

Soft skills:

- Cultura geral;

- Polivalência;

- Criatividade;

- Iniciativa;

- Atualização;

- Facilidade de perceção;

- Discrição;

- Ética;

- Dinamismo;

- Inovação;

- Visão sistémica. 


\section{Apresentação e discussão de resultados}

Após a análise do corpus documental definido (28 relatórios de estágio), foram obtidos os dados que passamos a apresentar de forma sistematizada.

\begin{tabular}{|c|c|c|c|c|c|}
\cline { 2 - 6 } & \multicolumn{3}{c|}{ TOTAL DE ALUNOS } & \multicolumn{2}{c|}{$\begin{array}{c}\text { ALUNOS QUE OPTARAM PELA } \\
\text { REALIZAÇÃO DE ESTÁGIO }\end{array}$} \\
\cline { 2 - 6 } & ALUNOS & H & M & H & M \\
\hline $\mathbf{2 0 1 2 - 2 0 1 3}$ & 28 & 4 & 24 & 0 & 6 \\
\hline $\mathbf{2 0 1 3 - 2 0 1 4}$ & 11 & 5 & 6 & 0 & 0 \\
\hline $\mathbf{2 0 1 4 - 2 0 1 5}$ & 13 & 3 & 10 & 0 & 4 \\
\hline $\mathbf{2 0 1 5 - 2 0 1 6}$ & 8 & 3 & 5 & 0 & 3 \\
\hline $\mathbf{2 0 1 6 - 2 0 1 7}$ & 16 & 5 & 11 & 2 & 5 \\
\hline $\mathbf{2 0 1 7 - 2 0 1 8}$ & 15 & 4 & 11 & 1 & 7 \\
\hline
\end{tabular}

Tabela 1. Número de alunos inscritos na unidade curricular de Projeto/Estágio (2012-2018). Fonte: elaboração própria.

Como podemos verificar na figura 1, a unidade curricular permite ao aluno escolher uma de três modalidades de trabalho final para finalizar a sua licenciatura: 1) projeto em contexto organizacional, ou estágio, que implica a prática em contexto real de trabalho, numa entidade de acolhimento; 2) projeto de empreendedorismo, o qual promove o desenvolvimento da simulação de um plano de criação de um negócio; e 3) projeto de investigação-ação, sendo este um trabalho de maior ênfase na prática de investigação aplicada, tendo por base o tema pertinente para o desenvolvimento da profissão de secretário ou para o aprofundamento científico dessa área do saber e do saber-fazer.

\section{TIPOLOGIA DE PROJETOS}

Figura 2. Total de alunos que frequentaram a unidade curricular distribuição por tipo de projeto (20122018). Fonte: elaboração própria.

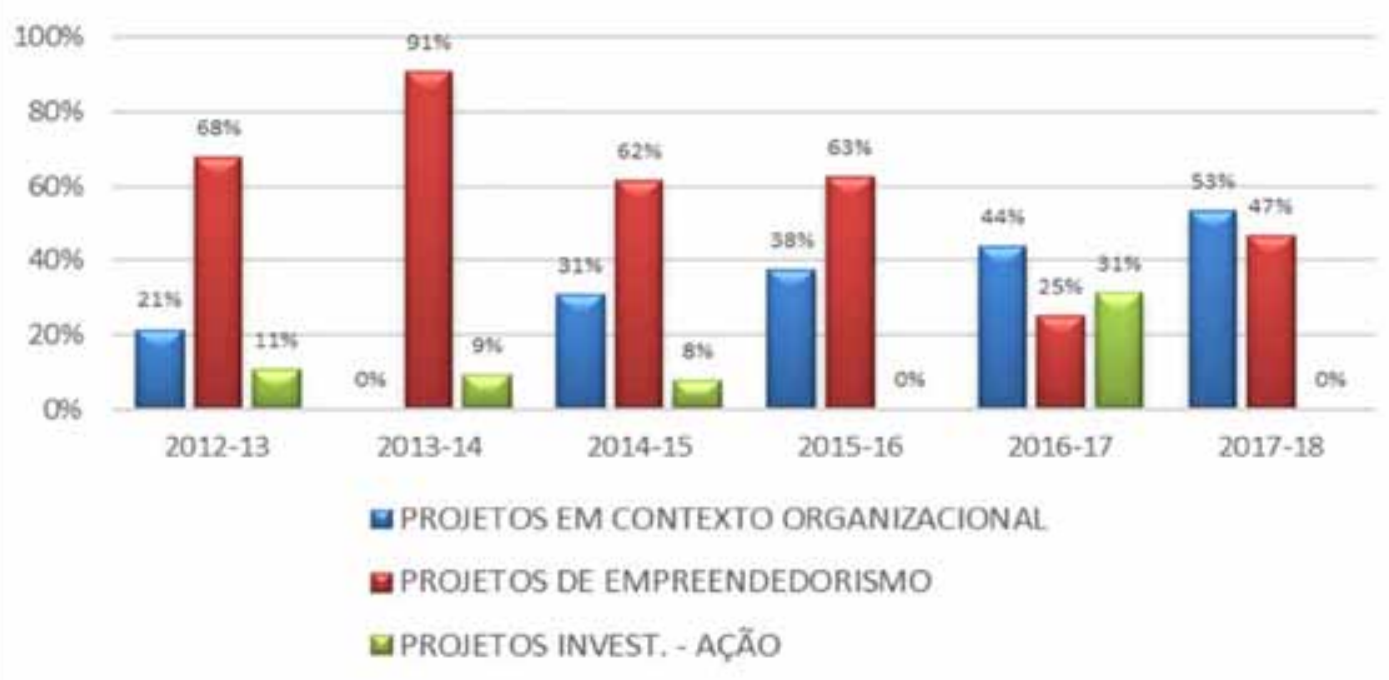


Conforme podemos verificar pela tabela 1 e pela figura 1, o número de alunos que têm optado pela realização de estágio tem vindo a acentuar-se. Esta situação explica-se por dois critérios, relacionados com a alteração do perfil do próprio aluno desta licenciatura na instituição, como já referimos: a) os alunos, que antes eram originários essencialmente dos concursos especiais (Concurso especial de ingresso para Maiores de 23 anos, Concursos de reingresso no ensino superior, etc.) passaram a provir do concurso nacional de ingresso, na sua maioria, tendo uma média de idades inferior e desenvolvendo um percurso "normal" de formação (desde o ensino básico até ao ensino superior); b) os alunos que tendencialmente optam pela realização de estágio não têm qualquer experiência de trabalho, pelo que desejam desenvolver esse primeiro contacto com a realidade profissional, pois consideram que a indicação da detenção de um estágio curricular poderá ser uma mais valia para, posteriormente, conseguirem ingressar no mundo laboral.

Da análise dos dados, conseguimos verificar que os alunos que frequentam a unidade curricular de Projeto/Estágio são, maioritariamente, do sexo feminino, sendo uma constatação óbvia, dado que, nos últimos anos letivos, o género predominante de inscritos nesta licenciatura corresponde também ao género feminino.

\section{GÉNERO}

\section{aHOMENS 픔 MULHERES}

Figura 2. Total de alunos que frequentaram a unidade curricular - distribuição por sexo (2012-2018). Fonte: elaboração própria.

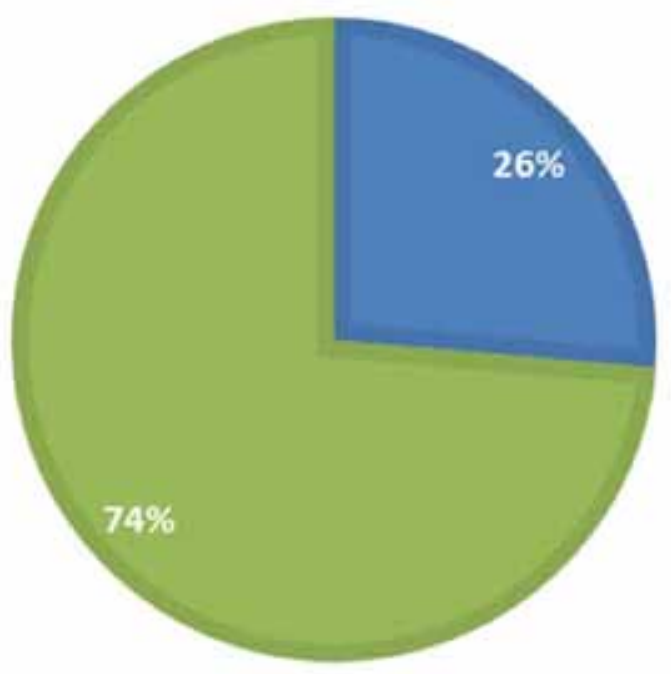

Como já referimos, a unidade curricular conta com três possibilidades de trabalho: Projeto em contexto Organizacional (objeto de estudo deste trabalho); Projetos de empreendedorismo e Projetos de investigação-Ação, verificando-se um aumento gradual do número de alunos que optam pelo projeto em contexto organizacional (estágio). 


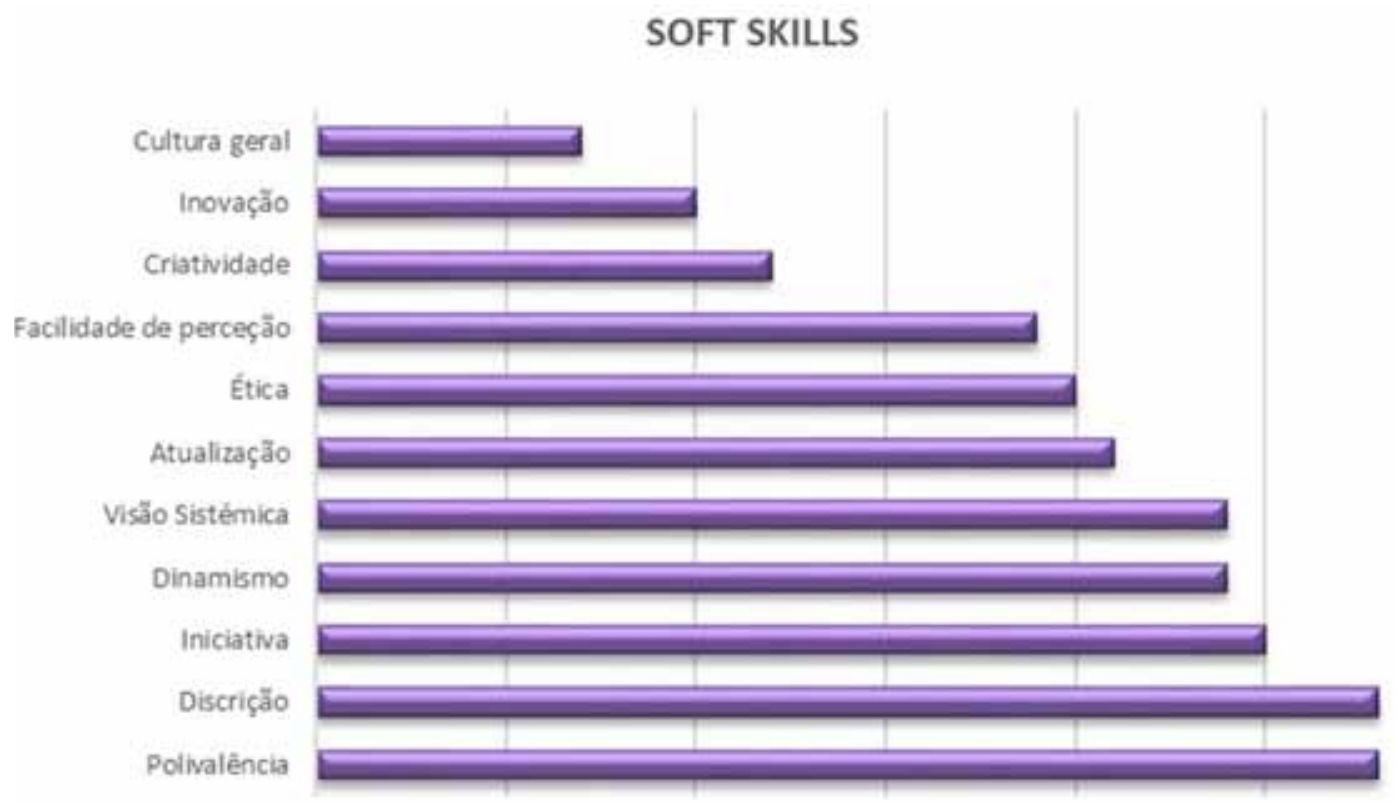

Figura 3. Alunos em projetos em contexto organizacional (2012-2018).

Fonte: elaboração própria.

As entidades de acolhimento no âmbito dos estágios dividem-se em três grandes áreas, conforme apresentado no gráfico 4 . Verificamos uma ligeira prevalência das organizações sem fins lucrativos (OSFL), não só pelo facto de o tecido empresarial na região não conter muitas empresas de média ou grande dimensão para garantir estágios que correspondam às exigências de uma licenciatura, mas também porque no grupo das OSFL estão englobadas entidades de diferentes tipologias e áreas (por exemplo: ordem dos Advogados, Museus, IPSS, entre outras).

Antes da realização de qualquer estágio, a docente responsável pela coordenação da unidade curricular negoceia com cada entidade, não só as tarefas com maior relevância em cada entidade de acolhimento (e que vão ao encontro das suas necessidades), mas também os objetivos gerais e específicos que cada aluno deve alcançar para poder concluir o seu estágio curricular.

Cada entidade de acolhimento indica a pessoa responsável (tutor) pelo aluno estagiário ao longo das 300 horas, o qual tem como deveres (ESTGL, 2018):

- Acolher o aluno e encaminhá-lo ao seu posto de trabalho;

- Propor, juntamente com a coordenadora da unidade curricular, o plano de trabalho que será confiado à aluna;

- Guiar e orientar o aluno nas tarefas a executar, de acordo com a planificação e objetivos definidos;

- Comunicar ao aluno as normas de trabalho, de segurança e higiene de acordo com a regulamentação do trabalho em vigor nessa organização; 
- Informar a docente coordenadora da unidade curricular de eventuais dúvidas, conflitos ou problemas que possam surgir durante o período do projeto.

\section{ENTIDADE DE ACOLHIMENTO}

m Org s/ fins lucrat. E Entidade Privada =Administração Pública

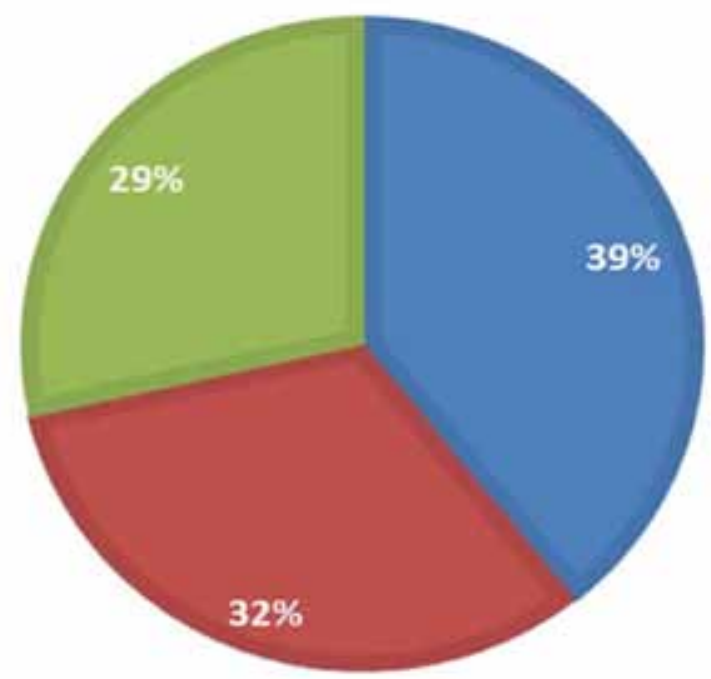

Figura 4. Entidades de acolhimento (2012-2018). Fonte: elaboração própria.

Após definidas as principais áreas de intervenção, o tutor e o docente orientador (docente encarregue por acompanhar o desenvolvimento do estágio e do respetivo relatório final, o qual pode ser o docente coordenador da unidade curricular ou outro docente do Conselho de Curso) definem formas de trabalho e intervenção e vão acompanhando o desenvolvimento de todas as tarefas e etapas (no início do semestre é definido, entre o docente coordenador e os alunos, um cronograma com a entrega faseada do relatório final).

Para uma melhor compreensão e sistematização das necessidades do mercado de trabalho e das competências que mais trabalhadas têm sido ao longo dos estágios, foi desenvolvida uma análise de conteúdo dos vinte e oito relatórios produzidos no período em estudo. Esta análise centrou-se essencialmente nas seguintes partes dos relatórios:

- Capítulo III - identificação dos objetivos gerais e específicos negociados com as entidades de acolhimentos, definindo as principais metas a alcançar pelo aluno;

- Capítulo V - análise das atividades e tarefas desenvolvidas, tendo em conta todas as ferramentas utilizadas para a sua realização;

- Capítulos VI e VII - verificação das propostas de melhoria introduzidas e propostas para o futuro para a entidade de acolhimento, bem como a reflexão crítica acerca do desempenho que cada aluno apresenta no final do seu relatório. 
De todos os documentos analisados, podemos afirmar que as competências técnicas mais solicitadas pelas entidades de acolhimento (conforme apresentado na Figura 5) são: a capacidade de organização, a capacidade de resolução de problemas, conhecimento e utilização de TIC, capacidade de gestão de tempo e gestão de fluxos de informação.

\section{COMPETÊNCIAS TÉCNICAS}

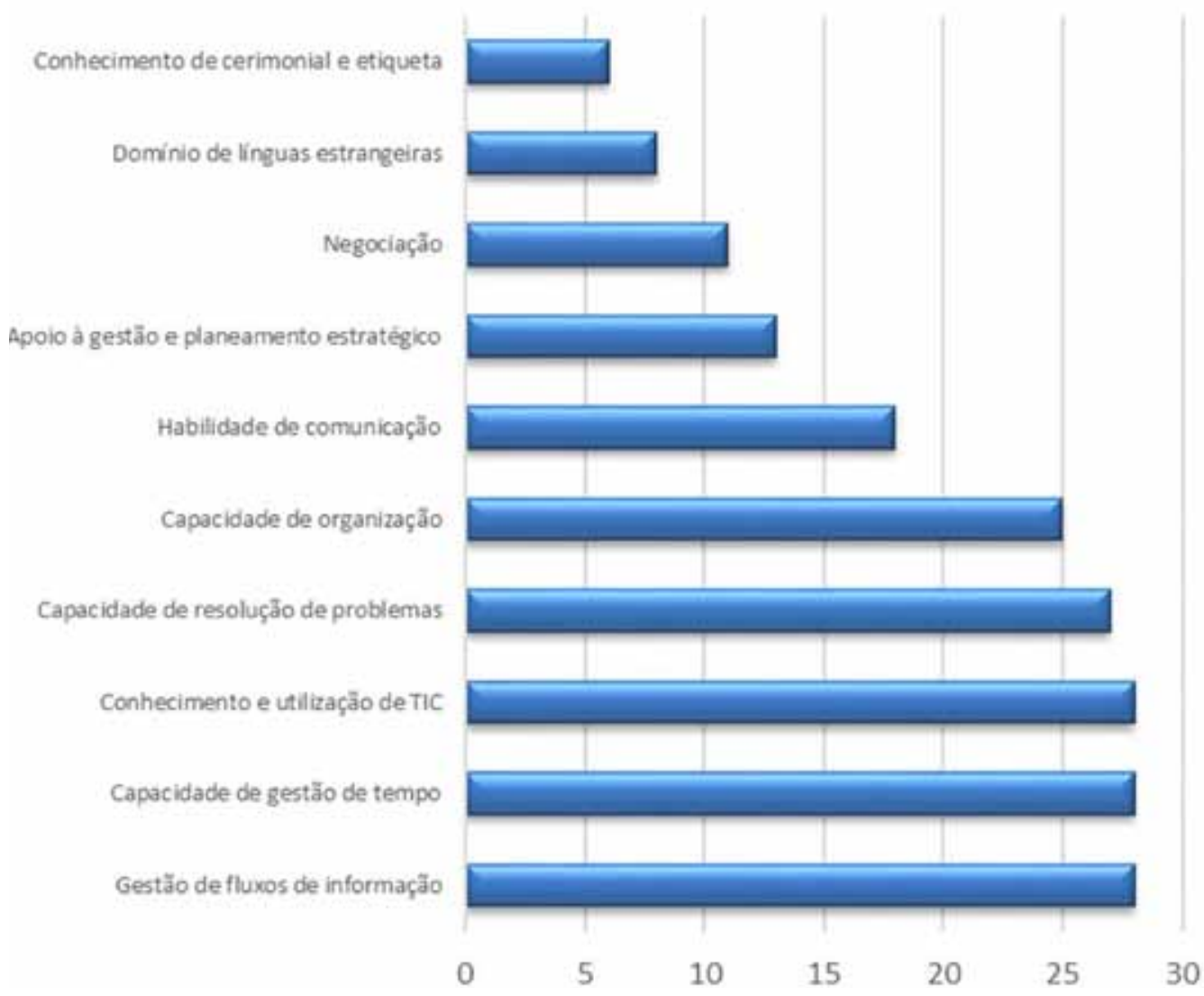

Figura 5. Competências técnicas (2012-2018). Fonte: elaboração própria.

Em relação às soft skills definidas (as quais estão também projetadas no programa e no regulamento de funcionamento da unidade curricular), aquelas que apresentaram maior relevância nos estágios foram: a polivalência, a discrição e ainda a capacidade de iniciativa, embora a maioria das restantes tenham tido também uma elevada verificação de ocorrência em grande parte dos relatórios observados.

Perante os dados recolhidos, percecionamos a importância do domínio de competências críticas para o desempenho da função de secretariado. Além disso, verificamos também a crescente importância de competências transversais e soft skills para o êxito desse mesmo desempenho, já que as características de um secretário contemporâneo exigem (como já analisámos) a conjugação de diver- 
sas áreas de saber e de capacidades comunicacionais (a diversos níveis e através de múltiplos canais), nunca descurando o sigilo profissional.

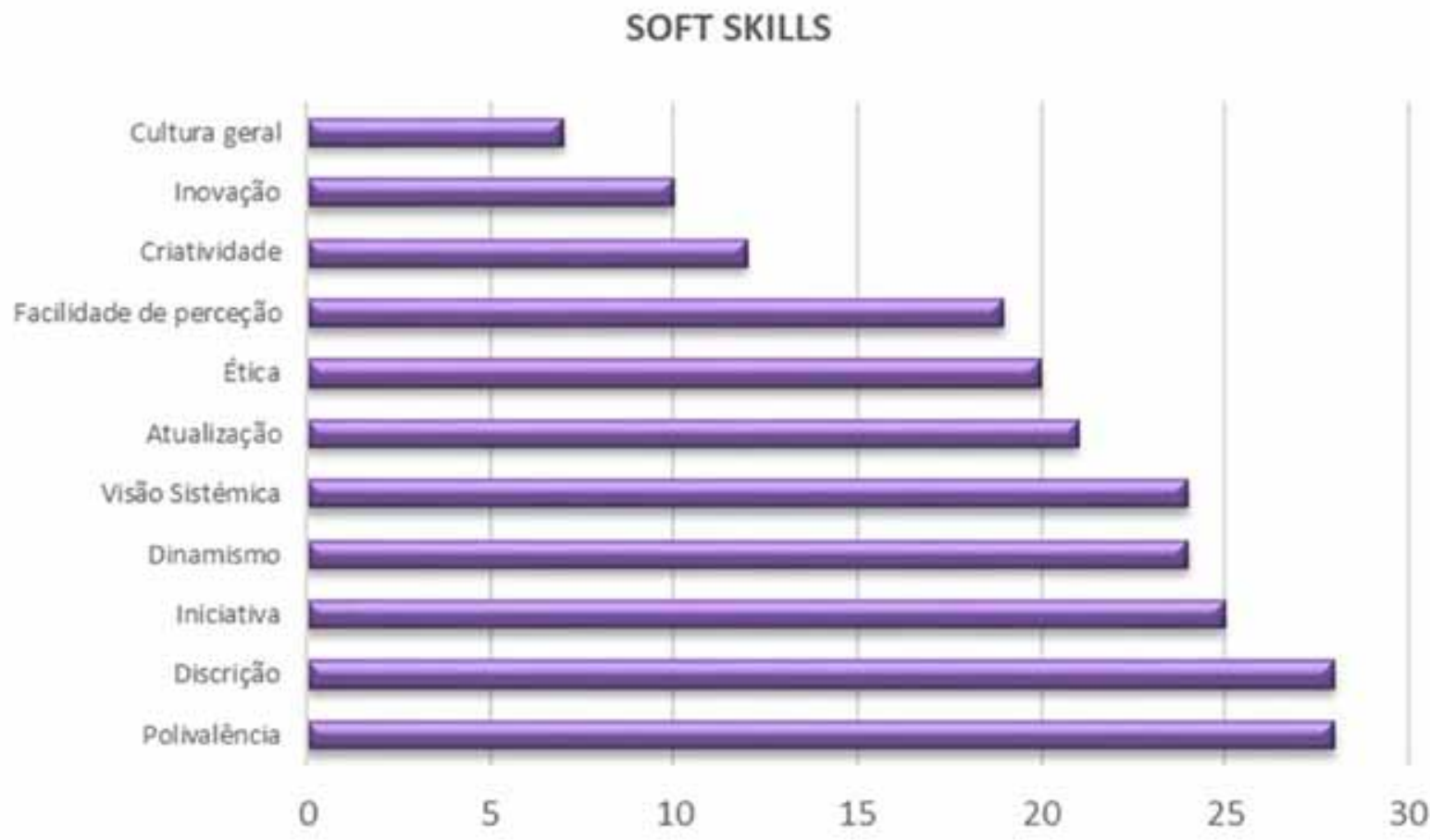

Figura 6. Soft Skills (2012-2018). Fonte: elaboração própria.

\section{Considerações finais}

A definição clara das competências e dos conhecimentos a serem adquiridos no final do percurso académico, no desenvolvimento de planos curriculares coerentes e adequados às necessidades do mercado de trabalho, permite $o$ desenvolvimento de formações superiores que garantam a empregabilidade dos futuros licenciados e a atratividade das próprias formações.

Qualquer licenciatura da área de Secretariado enfrenta o desafio de qualificar futuros profissionais capazes de desempenhar as suas funções em contextos profissionais completamente díspares, já que o trabalho de secretariado especializado e qualificado é necessário em todas as áreas económicas e tipologias de organizações. Isto é, a capacidade polivalente exigida ao secretário contemporâneo evidencia a sua capacidade de intervenção em múltiplos ambientes profissional, exigindo, portanto, uma formação multidisciplinar e o domínio de diferentes áreas do saber.

Desta primeira abordagem realizada, e apesar dos dados que apresentamos serem ainda básicos e limitarem-se apenas a uma das instituições de ensino superior, do subsistema politécnico, com formação na área estudada, consideramos ser já possível retirar alguns considerandos e apresentar propostas e mel- 
horias a introduzir na planificação e gestão dos estágios dos alunos finalistas da licenciatura em apreço:

Aquando da negociação das tarefas a desenvolver (tarefa realizada pelo docente coordenador da unidade curricular, de acordo com o perfil de cada aluno), cada entidade de acolhimento do estágio deverá também identificar claramente quais as principais competências que podem ser trabalhadas durante o período de estágio, de acordo com a área económica onde desenvolve a sua atividade.

No final de cada estágio, poderá ser feita a confirmação dessa informação (ou seja, a verificação das competências nucleares a transversais trabalhadas) através do levantamento desses dados junto da entidade de acolhimento, do tutor e do próprio aluno. A confirmação das competências deve ser baseada em evidências, através de documentação elaborada e/ou recolhida ao longo da realização do período de estágio, por cada aluno.

Apesar destas propostas de melhoria que queremos implementar, para que nos seja possível um estudo mais aprofundado e acurado, consideramos que os resultados apresentados demonstram a pertinência de uma formação e qualificação multidisciplinar nesta licenciatura.

De facto, pensar assessoria e secretariado na atualidade exige conhecer todos os desafios de um mercado globalizado, onde os futuros profissionais poderão desenvolver a sua função de apoio especializado ao executivo, desde micro e pequenas empresas (com uma capacidade de atuação meramente local), até a organizações de cariz multinacional ou internacional, que desempenhem um papel central nas relações internacionais (de natureza económica, política, humanitária ou social, entre outras) e, pela sua natureza, exijam um apoio de secretariado com capacidade de desempenho multicultural, multilinguístico e com competências diretas em múltiplas áreas do saber, desde o direito até à contabilidade e diplomacia.

Perante todos estes cenários, os estágios curriculares, sendo muitas vezes, a primeira abordagem ao mundo do trabalho, deverão preocupar-se em conceder aos alunos uma capacidade de mundividência, onde eles sejam capazes de, utilizando quadros de pensamento e conhecimento abstratos, conseguirem pensar criticamente cada situação e definirem estratégias de intervenção e de resolução. 


\section{Referências bibliográficas}

Bardin, L. (2011). Análise de conteúdo (5 $5^{\mathrm{a}} \mathrm{ed}$.). Lisboa: Edições 70.

Cabrera-Jimenez, M. (2020). Relevancia de las competencias ciudadanas en construcción de civilidad en educación superior. Educación y Humanismo, 22(38), 1-24. https:/ / doi. org/10.17081/eduhum.22.38.3555

Camara, P. B. da. (2017). Dicionário de competências. Lisboa: RH Editora.

Comissão Europeia. (2009). Quadro Europeu de Qualificaçôes para a aprendizagem ao longo da vida (QEQ). Luxemburgo. https:/ / doi. org/10.2766/26704

Despacho (extrato) n. ${ }^{\circ} 4684 / 2016$, Pub. L. No. Diário da República n. ${ }^{\circ}$ 66/2016, Série II de 2016-04-05 (2016). Disponível em https:// dre.pt/web/guest/home/-/dre/74047034/ details $/ 2 /$ maximized?serie $=I I \& p a r t e$ filter $=33 \&$ day $=2016-04-05 \&$ date $=2016-04-$ 01\%2Fen\&dreId=74042329

ESTGL. (2018). Modelo geral de protocolo para projetos em contexto organizacional. Lamego.

ESTGL. (2019). Processo PERA - Pedido Especial de Renovação de Acreditação da licenciatura de Secretariado de Administração. Lamego. Disponível em http://www.estgl.ipv.pt/ avaliacao_qualidade/PERA_1718_0027876_ SA.pdf $\% 0 A$

European Ministers in charge of Higher Education. (1999). The Bologna Declaration of 19 June 1999: Joint declaration of the European Ministers of Education | EURASHE. Bologna. Disponível em https://www.eurashe.eu/library/ bologna_1999_bologna-declaration-pdf/

Fleury, M. T. L., \& Fleury, A. (2001). Construindo o conceito de competência. Revista de Administração Contemporânea, 5(spe), 183-196. https://doi.org/10.1590/s141565552001000500010
Fortin, M.-F. (2000). O Processo de Investigação. Loures: Lusociência - Edições Técnicas e Científicas, Lda. Disponível em https://www. fnac.pt/O-Processo-de-Investigacao-MarieFabienne-Fortin/a176574

Le Boterf, G. (2001). Ingeniería de las competencias. Spain: Gestión 2000.

Lei n. ${ }^{\circ}$ 49/2005 de 30 de Agosto da Assembleia da República, Pub. L. No. Diário da República n. ${ }^{\circ}$ 166/2005, Série I-A de 200508-30 (2005). Lisboa. Disponível em https:/ / dre.pt/pesquisa/-/search/245336/details/ maximized

Martínez, M. F. C., Mendoza Velazco, D. J., Cejas, M. N., Villacis, J. L. R., \& Freire, Y. M. O. (2019). A PerformanceCentred Competency-Based Approach to Quality University Teaching. Integration of Education, 23(3), 350-365. https://doi.org/10.15507/19919468.096.023.201903.350-365

Perrenoud, P. (1999). Construir as competências desde a escola. Porto Alegre: ARTMED.

Ramos, E., \& Bento, S. (2006). As competências: quando e como surgiram. In Gestão e Desenvolvimento de Competências. Lisboa: Sílabo.

Santos, P. M. (2019). Secretariado e Estratégia Organizacional: Assessoria, Gestão de Eventos e Planeamento Estratégico. Viseu: Edições Esgotadas. Disponível em https://www. edicoesesgotadas.com/catalogo/secretariadoe-estrategia-organizacional/

Santos, P. M., \& Bonito, Á. (2010). Interagir com o mundo do trabalho - o ensino colaborativo e o voluntariado. In Actas do Congresso Ibérico Ensino Superior em Mudança: Tensões e Possibilidades. Braga: Universidade do Minho.

Spencer, L., Mcclelland, D. C., \& Spencer, L. (1990). Competency assessment methods: history and 
state of the art. London: Hay McBer Research Press. Disponível em https://www.amazon. com/Competency-assessment-methodsHistory-state/dp/B0006RCBCC

Vandeweerd, J.-M., Cambier, C., Romainville, M., Perrenoud, P., Desbrosse, F., Dugdale, A., \& Gustin, P. (2014). Competency Frameworks: Which Format for Which Target? Journal of Veterinary Medical Education, 41(1), 27-36. https://doi.org/10.3138/ jvme.0413-062R1 